
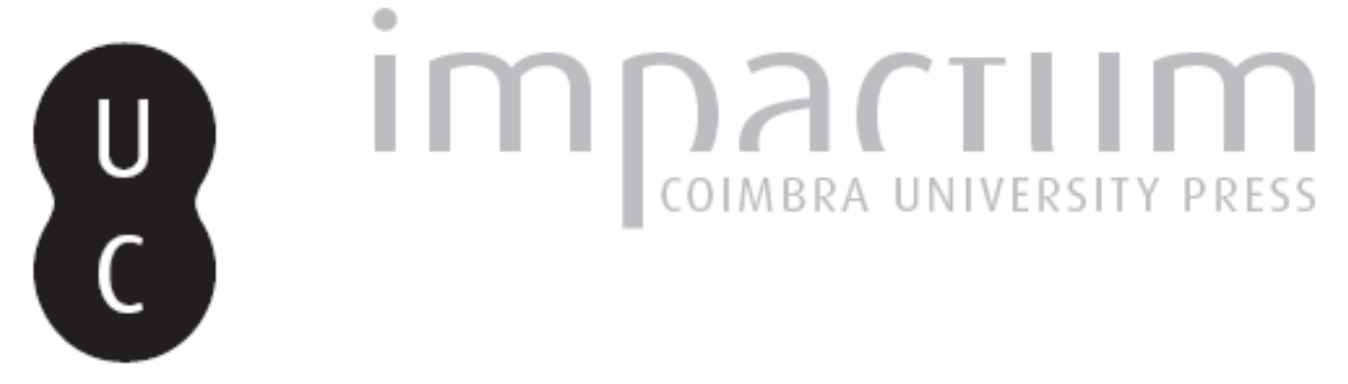

\title{
O leviatã da política externa da UE e a cidadania comprometida
}
Autor(es): $\quad$ Almeida, Miguel da Costa Paiva Régio de
Publicado por: Centro de Informação Europe Direct de Aveiro; Centro de Estudos Interdisciplinares do Século XX

URL

persistente:

URI:http://hdl.handle.net/10316.2/33978

DOI:

DOI:http://dx.doi.org/10.14195/1647-6336_11_7

Accessed : $\quad$ 26-Apr-2023 14:58:09

A navegação consulta e descarregamento dos títulos inseridos nas Bibliotecas Digitais UC Digitalis, UC Pombalina e UC Impactum, pressupõem a aceitação plena e sem reservas dos Termos e Condições de Uso destas Bibliotecas Digitais, disponíveis em https://digitalis.uc.pt/pt-pt/termos.

Conforme exposto nos referidos Termos e Condições de Uso, o descarregamento de títulos de acesso restrito requer uma licença válida de autorização devendo o utilizador aceder ao(s) documento(s) a partir de um endereço de IP da instituição detentora da supramencionada licença.

Ao utilizador é apenas permitido o descarregamento para uso pessoal, pelo que o emprego do(s) título(s) descarregado(s) para outro fim, designadamente comercial, carece de autorização do respetivo autor ou editor da obra.

Na medida em que todas as obras da UC Digitalis se encontram protegidas pelo Código do Direito de Autor e Direitos Conexos e demais legislação aplicável, toda a cópia, parcial ou total, deste documento, nos casos em que é legalmente admitida, deverá conter ou fazer-se acompanhar por este aviso.

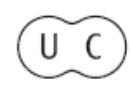


DEBATER

A EUROPA

jul-dez 2014

QUE EUROPA(S)?

CONTEXTOS E DESAFIOS 


\title{
O Leviatã da Política Externa da UE e a Cidadania comprometida
}

\author{
Miguel da Costa Paiva Régio de Almeida \\ Doutorando FDUC \\ E-mail: miguel.regio.almeida@gmail.com
}

\begin{abstract}
Resumo
Propomo-nos cogitar o papel do cidadão na constituição do corpo macro-estadual da UE e a forma como a perceção do primeiro é afetada pela Política Externa do segundo, destacando a assunção de uma crescente faceta hobbesiana nesta interação. Designadamente no que toca às estratégias da Realpolitk e à sua dimensão belicista, apresentamos uma breve resenha deste Leviatã e refletimos sobre algumas questões potencialmente prejudiciais à cidadania europeia. Palavras-chave: Cidadania; Política Externa; Thomas HobBes; Belicismo; Realpolitik
\end{abstract}

\begin{abstract}
We propose to look at the citizen's role in the constitution of the EU macro-state body and the way in which the perception of the first is affected by the Foreign Policy of the second, highlighting the assumption of a growing hobbesian face within this interaction. Namely in what is due to the Realpolitk strategies and its warlike dimension, we present a brief description of this Leviathan and reflect on some issues potentially damaging to the European citizenship.
\end{abstract}

Keywords: Citizenship; Foreign Policy; THOMAs HoBBEs; Warmongering; Realpolitik

\section{O Leviatã da Política Externa da UE e a Cidadania comprometida}

Importante figura da mitologia judaica, o Leviatã é uma serpente marinha primordial, que podemos associar ainda ao Monstro de Loch Ness ou ao Kraken do folclore nórdico. Esta imagem interessa-nos naturalmente na senda do caracterizado por THOMAS HOBBES em 1651 
no seu projeto de erigir uma Ciência Política, apelidando de Leviathan o governo central, que concentraria todo o poder em seu redor, de modo absoluto, priorizando a Segurança.

O cidadão no modelo hobbesiano, longe do participativo e diligente do modelo republicano-aristotélico, é aquele que colhe a absoluta submissão ao Soberano. ${ }^{1}$ Ao delegarem a sua vontade política no Governo/Commonwealth/Leviathan, os cidadãos-súbditos perdem todos os seus direitos, com exceção daqueles que o Governo lhes conceder. O que importa a HoBBEs é a concentração de poderes numa só figura, seja homem ou assembleia: esta é o Soberano. ${ }^{2}$ O Soberano é absoluto, não admitindo oposições, devendo regular o comércio externo e não sendo sujeito à lei civil. ${ }^{3}$ Ademais, todos os encarregados pela Educação devem exercer o seu magistério ensinando apenas o que o Soberano achar útil, operando como seus ministros. ${ }^{4}$ À semelhança do doutrinamento da religião cristã, também a submissão ao Soberano devia ser ensinada ao povo, cuja reta e supervisionada instrução caberia primevamente às universidades. ${ }^{5}$ Temos assim, na senda do modelo já enunciado por PlATÃo na Politeia, o claro operar da manutenção de uma ideologia oficial.

Neste quadro seminal da Ciência Política, de que modo surge o cidadão no contexto da União Europeia (UE)? Certamente que, não tendo voz a ser ouvida quanto às questões da Política Externa, a opção participativa é colocada de lado, restando-lhe assistir às estratégias dos macro-decisores políticos aos quais se submete. Efetivamente, quer o deseje ou não, tem delegadas noutras instâncias a realização da sua voluntas política. Contudo, carreando a égide do Estado - ou da Federação ou União de Estados - no qual está inserido, sujeita-se a que recaia sobre si próprio a ideia, o louvor, a represália, et caetera, que o "outro" não-europeu tenha sobre a imagem do cidadão da UE em abstrato. E se às vezes observamos mediatizada uma aura benéfica ${ }^{6}$, por outro podemos ter que lidar com a face infamante do antieuropeísmo, tão semelhante ao anti-americanismo.

Será este um receio infundado? Afinal que imagem recai sobre o cidadão europeu? Mesmo sem grandes possibilidades de pronúncia, e muito menos de ascese ao domínio da

\footnotetext{
${ }^{1}$ Thomas Mautner, The Penguin Dictionary of Philosophy (ed.). London: Penguin, 1997. Trad. Dicionário de filosofia, Coimbra: Edições 70, 2010: p. 370.

${ }^{2}$ ThOMAS HoBBes, Leviathan, 1651; ed. London: Penguin, 1985 (reimpressão): p. 260; BERTRAND RUSSELL, History of Western Philosophy, London: Allen \& Unwin, 1945; ed. London: Routledge, 2010: pp. 505-506.

${ }^{3}$ HobBes, op. cit.: p. 313.

${ }^{4}$ Ibidem: pp. 233-234, 291, 379-386.

${ }^{5}$ RUSSEL, op. cit.: pp. 507-508.

${ }^{6}$ Afirmou já FREITAS DO AMARAL que "o papel da Europa no mundo não pode deixar de ser tido como absolutamente essencial, para ajudar a resolver, em paz e na justiça, a "nova questão social" do século XXI, o conflito Norte-Sul à escala planetária." (Id., Uma Presidência Portuguesa da Assembleia Geral da ONU, in «Nação e Defesa: "Evolução das Nações Unidas"», Instituto da Defesa Nacional, no 104, Primavera 2003, $2^{\text {a }}$ Série, pp. 49-63: p. 56)
} 
Realpolitik, o cidadão-comum é uma parte componente do Estado, um elemento vivo do organismo do Soberano, que sofre o ricochete das ações do Leviatã. De modo a tentar responder a tais cogitações (4.), importa primeira e brevemente recordar o caminho percorrido nas últimas décadas em matéria de Segurança (1.), mirando a realidade presente do teatro de operações bélico (2.), e tendo sempre consciência do amplo horizonte institucional e de áreas e mecanismos de intervenção com que lidamos (3.).

\section{Um exercício de memória recente sobre a Segurança}

Deparamo-nos mormente com um problema algo paradoxal: se se assume que, apud NiETZSCHE e ORTEGA Y GASSET, o Homem é um "ser de memória", cuja maior riqueza é o tesouro dos seus erros ${ }^{7}$, também é verdade que no plano internacional existe uma generalizada "falta de memória", que se reflete negativamente nas ações político-diplomáticas. ${ }^{8}$ É contrariando esta, indo destarte ao encontro daqueles dois filósofos, que nos importa fazer aqui uma breve resenha histórica.

No cenário europeu do pós-II Grande Guerra, as circunstâncias e a contínua reorganização da comunidade internacional levaram a que a Segurança fosse considerada um assunto tabu entre os Estados-Membro (EM) por mais de três décadas ${ }^{9}$, o que ademais justificou $a b$ initio a feição essencialmente económica da então Comunidade. Foi a partir da década de 80 do século passado que se intensificaram os esforços conducentes ao reconhecimento do interesse e competência comunitárias nesta matéria, faceta aliás necessariamente decorrente da integração política operada desde a década de 70.

O Parlamento Europeu protagonizou aqui um grande papel impulsionador, consagrando-se com o Ato Único Europeu (1987) uma nova base de legitimação para lidar com a política de segurança. A integração desta com a Organização do Tratado do Atlântico Norte (OTAN) é oficialmente declarada: “[a] Europa Ocidental deverá, no futuro, elaborar em conjunto análises globais em relação a todas as questões importantes no âmbito da política de defesa, de controlo de armamentos e de desanuviamento, sintetizar princípios fundamentais e a partir daí formular exigências e propostas concretas, que deverão ser concertados com o

\footnotetext{
${ }^{7}$ ORTEGA y GASSET, La rebelión de las masas, Buenos Aires: Colección Austral, 1937. Trad. A rebelião das massas, Lisboa: Relógio D’Água, 1989: p. 32.

${ }^{8}$ António MonteIro, A Experiência Portuguesa na Presidência do Conselho de Segurança das Nações Unidas, in «Nação e Defesa: "Evolução das Nações Unidas"», Instituto da Defesa Nacional, no 104, Primavera 2003, 2 $2^{\text {a }}$ Série, pp. 81-95: p. 94.

${ }_{9}^{9}$ Audição pública sobre política de segurança na Europa - Situação e Previsões. Luxemburgo: Serviço das Publicações Oficiais das Comunidades Europeias, 1987: p. 6.
} 
Governo americano." ${ }^{10}$ Dado o colossal conflito ideológico da época, a assunção de uma posição definida está igualmente clarificada: “[a] Europa Ocidental deveria, sobretudo, poder defender os seus interesses perante o seu adversário ideológico e geopolítico, a União Soviética, dum modo mais sereno, confiante e seguro e com maiores probabilidades de sucesso". 11

O desejo de uma Europa segura consistia na apologia de um estádio em que a utilização da força armada seria perfeitamente dispensável para dirimir conflitos internacionais. ${ }^{12}$ Não obstante, os EM relacionavam-se mais autonomamente com a OTAN, não só pela falta de uma identidade comum, mas pela polarização na matéria nuclear. Por outro lado, após a queda do regime soviético, os interesses bélicos do Ocidente, nomeadamente os dos EUA, afastaram-se da sua matriz ideológica para se concentrar na necessidade de recursos energéticos, designadamente gás natural e petróleo. Assim, se antes interessavam os territórios do Centro e Sudeste Europeu e do Extremo Oriente, a partir de 1999 tornou-se prioritário para o Pentágono o controlo ou determinante influência no Golfo Pérsico, no Mar Cáspio e no Mar do Sul da China. Esta mudança de orientação naturalmente que se repercutiu por todo o globo, condicionando as prioridades da política externa de outras grandes potências, como a Rússia, a China e a UE, e trazendo para o palco central das atenções os países produtores destes recursos. ${ }^{13}$

Compreensivelmente, também a organização e o próprio entendimento da política de defesa se foi paulatinamente alterando, passando-se das plataformas de exército ostensivas, de grande dimensão, típicas da Guerra-Fria, para as unidades mais pequenas, de célere capacidade interventiva, que podem ser facilmente mobilizadas para todos os cantos do globo, e assim adaptadas aos tipos de confrontos que começaram a marcar a década de 90 do séc. XX (Ruanda, Bósnia, Kosovo, etc.). Revelou-se inclusive aconselhável o desenvolvimento conjunto dos materiais bélicos, o que era economicamente mais rentável, até pelas lições tiradas no contexto da OTAN. Não só se diminuem os custos, como se estimula a melhor integração das diversas forças, promovendo a racionalização das suas capacidades e a remoção de obstáculos logísticos. Benefícios que se refletem desde logo nos orçamentos dos diversos EM, assim menos onerados. ${ }^{14}$

\footnotetext{
${ }^{10}$ Ibidem: pp. $15-16$.

11 Ibidem: p. 16.

12 Ibidem: p. 42.

${ }^{13}$ MiCHAEL T. KLARE, The New Geography of Conflict, in «Foreign Affairs», vol. 80, n. ${ }^{\circ}$ 3, May-June 2001, pp. 49-61: pp. 49-52.

${ }^{14}$ STEPHEN PULlinger, Defence Equipment for European crisis management, in «Political Series», POLI 123 EN, Luxemburg: European Parliament, 2003: p. 56.
} 
Na verdade, a consciência da necessidade de uma política externa una está no próprio código genético da UE, quando em 1954 os seis founding fathers erigiram a Comunidade Económica Europeia, tendo antes cogitado criar uma Comunidade Europeia de Defesa. A Cooperação Política Europeia iniciou-se em 1970, tentando-se unificar as posições dos EM. O passo seguinte ficou consagrado em 1993 com o Tratado de Maastricht, através da Política Externa e de Segurança Comum (PESC), decorrente de décadas de crescimento económico e da consequente inflação dos interesses político-diplomáticos, auxiliado pelo ambiente belígero que pautou o espaço europeu naquelas décadas, nomeadamente até à queda do Muro, da URSS e da Jugoslávia. Com a PESC definiram-se as competências na tomada de ações políticas e diplomáticas na prevenção e resolução de conflitos.

O fracasso de diversos esforços diplomáticos durante a década de 90 do século passado levou a que se alterasse a Política Europeia de Segurança e Defesa [(PESD), um dos pilares da PESC)], realizando-se as primeiras incursões militares já em 2003, nos Balcãs, e depois na República Democrática do Congo. Consequentemente, a PESD demanda a manutenção de uma força militar da UE, distinta da OTAN, mas com acesso aos seus recursos. Estes efetivos, se secundariamente podem integrar forças de polícia locais, têm como primado missões de gestão de crises (humanitárias e de salvamento), de manutenção e restabelecimento da paz. Contudo, o recurso a esta força militar revelou-se menos frequente que o inicialmente esperado, dado que as decisões nevrálgicas dependem da unanimidade da votação, o que pode ser difícil de obter em querelas bélicas de natureza duvidosa, como a burlesca invasão do Iraque conduzida pelos EUA.

Posto isto, a UE não dispõe assim de um exército "completo" no sentido tradicional, de grandes dimensões e plenamente atuante nos diversos meios. A própria previsão nos Tratados anteriores era deveras limitadora, porque mui vaga: nomeadamente, a diferença abissal que havia na capacidade militar dos diversos EM inquinaria operações conjuntas de maior dimensão. Como sabemos, o Tratado de Lisboa destaca-se aqui como um importante marco, pois os Tratados compreendem agora uma maior densificação legislativa, consagrando os artigos $21^{\circ}$ a $46^{\circ}$ do TUE as Disposições gerais relativas à acção externa da União e disposições específicas relativas à política externa e de segurança comum.

Não obstante, importa destacar o artigo 24\%3 TUE, que nos remete para aquela dimensão absolutista hobbesiana do Soberano, quando consagra que

“Os Estados-Membros apoiarão activamente e sem reservas a política externa e de segurança da União, num espírito de lealdade e de solidariedade mútua, e respeitam a acção da União neste domínio. 
Os Estados-Membros actuarão de forma concertada a fim de reforçar e desenvolver a solidariedade política mútua. Os Estados-Membros abster-se-ão de empreender acções contrárias aos interesses da União ou susceptíveis de prejudicar a sua eficácia como força coerente nas relações internacionais."

Julgamos que estes desenvolvimentos deveriam ser mais do conhecimento público, não só por uma questão de transparência por parte da UE, mas também porque ajudará a fomentar a ausente "consciência comunitária", dado ser a defesa da Segurança um interesse partilhado comunitariamente por todos os cidadãos. Cogitamos ainda que esta mesma faceta contribui para a definição a identidade da UE na própria comunidade internacional, enquanto participante singular na Nova Ordem Mundial. Como observámos, não foi assim há tanto tempo que, num confronto ideológico, a Comunidade se encontrava plenamente submissa às decisões da OTAN e dos EUA porque a tecnologia do armamento em causa era a nuclear. ${ }^{15}$ Não são de descurar, obviamente, os factos de que a polarização noutros meios militares e o relativo descompromisso no nuclear são um grande contributo neste campo, mas, mais do que na inelutável capacidade objetiva material, pensamos na expressão política que se afirmaria.

\section{O teatro de operações bélicas: RAM e EMP}

Narrada brevemente a recente História institucional, urge mirar o real teatro de operações bélico. Assim, há que desde logo atentar na «Revolução nos Assuntos Militares» (RAM), conceito consagrado em 1991 com a Guerra do Golfo e que consiste, sumariamente, no processo de acelerada transformação dos meios militares dadas as pujantes evoluções tecnológicas, nomeadamente na eletrónica e na informática. Tal revolução determinou uma nova conceção de guerra, seja no seu cariz social ou na sua face político-estratégica. ${ }^{16}$

É certo que a História militar foi continuamente perpassada por revoluções análogas, seja com o arco-e-flecha e a pólvora ou a guerra nuclear e a conquista e militarização do Espaço, inovações materiais que se interligam com as transformações político-económicosociais. ${ }^{17}$ A RAM não é mais que um reflexo da superioridade dos EUA em matéria militar,

\footnotetext{
${ }^{15}$ AndRÉ Dumoulin, Nuclear Weapons and European Defence Identity, «Political Series», Working Document for the Directorate-General for Research of the European Parliament, Brussels: European Parliament, 1996: p. 88.

${ }^{16}$ CARlos SANTOS PEREIRA, A RAM: Realidade e Utopia, in «Nação e Defesa: "Evolução das Nações Unidas"», Instituto da Defesa Nacional, no 104, Primavera 2003, 2 ${ }^{a}$ Série, pp. 149-183: p. 151.

${ }^{17}$ Fala-se inclusive da guerra em três vagas: a vaga das "guerras agrárias" - fruto da revolução neolítica; a das "guerras industriais" - produto da revolução industrial; e a vaga da "guerra da informação" (Information Warfare), consequência da revolução eletrónica. Esta última desenvolve-se, sumariamente, em dois grandes
} 
política e económica. Novos campos táticos ganharam relevo: para além do "ciberespaço" da informação, os sectores de Civil e Public Affairs assumem uma maior preponderância, tornando a guerra eletrónica e a guerra psicológica ainda mais pertinentes. Encontramo-nos no império da racionalidade instrumental ${ }^{18}$, impondo-se a concorrência do mercado e a competição tecnológica como novas formas de valorização militar, o que leva também a que se esbata a autoridade militar sobre os engenheiros (civis) empregados.

Outra consequência da RAM é a contínua "fuga em frente", idem est, a incessante prossecução da supremacia tecnológica militar e a sua consequente escalada orçamental, a absolutização da "guerra da informação" e a vera desumanização do conflito. O que conduz à polarização extremada da dialética entre os EUA e o resto do Mundo. Referimo-nos à coadunação da face militar com a política num claro bicefalismo estadunidense, que leva a tomar como potencial adversário qualquer competidor económico, designadamente nas tecnologias de ponta, deixando em delicada posição a UE, o Japão, a Rússia e a China. Esta Nova Ordem Mundial reflete-se também no intencionado monopólio da militarização do Espaço, como se de um solipsismo norte-americano se devesse tratar. Em situação limite, a RAM leva à dispensa de aliados ou de coligações. Se fatores como o Tempo e o Espaço se relativizam; se diminui a dependência de recursos geoestratégicos tradicionais como aeroportos, portos marítimos, et caetera; se se abre um fosso entre as capacidade militares das forças aliadas ${ }^{19}$... que necessidade, a longo prazo, terão os EUA de conjugar a sua Política Externa nesta matéria com a ONU, a OTAN e, em última análise, a UE!?

A RAM pode ser um fenómeno marcadamente americano, mas traz implicações - ou complicações - às estratégias de defesa europeias. Desde já a nível orçamental, na promoção ou limitação do desenvolvimento tecnológico militar. Tanto que em 1998 foi criado o Organisme Conjoint de Coopération en Matière d'Armement (OCCAR) pela França, Alemanha, Itália e Reino Unido, contando com a adesão de muitos outros EM posteriormente. O objetivo desta congregação é a concertação de esforços no desenvolvimento de materiais

\footnotetext{
momentos: em primeiro lugar a Reconnaissence, Intelligence, Surveillance and Target Acquisition (RISTA) e posteriormente a Long Range Precision-Guided Munitions (LRPGM).

${ }^{18}$ Estas transformações modificam a noção do tradicional soldado no séc. XXI. Mais do que o equipamento futurista de laivos cyberpunk a que os exércitos têm acesso - que incorpora sistemas de camuflagem automática, melhoramento do seu desempenho muscular/atlético, armamento altamente especializado e compacto ou equipamento informático que permite uma mobilidade estratégica sem precedentes em tempo real - há que cogitar no facto de que esta profissionalização das forças militares no Ocidente cinde a era do "povo em armas", do "cidadão soldado", o que conduz a uma certa mercenarização e empresarialização de tais forças, dissociandoas da sua tradicional função social, enquanto correspondentes da vontade popular. (CARLOS PEREIRA, op. cit.: pp. 159 e ss.)

${ }^{19}$ Ibidem: pp. 179-182.
} 
militares e a aplicação de medidas competitivas para diminuir o custo da despesa dos equipamentos de defesa. ${ }^{20}$

Por seu lado, os Tratados também refletem a dificuldade do compromisso em mãos, dispondo desde logo o artigo 42\% $/ 3$ TUE que

"Com vista à execução da política comum de segurança e defesa, os EstadosMembros colocam à disposição da União capacidades civis e militares de modo a contribuir para os objectivos definidos pelo Conselho. Os Estados-Membros que constituam entre si forças multinacionais podem também colocá-las à disposição da política comum de segurança e defesa.

Os Estados-Membros comprometem-se a melhorar progressivamente as suas capacidades militares. A agência no domínio do desenvolvimento das capacidades de defesa, da investigação, da aquisição e dos armamentos (a seguir denominada «Agência Europeia de Defesa») identifica as necessidades operacionais, promove as medidas necessárias para as satisfazer, contribui para identificar e, se necessário, executar todas as medidas úteis para reforçar a base industrial e tecnológica do sector da defesa, participa na definição de uma política europeia de capacidades e de armamento e presta assistência ao Conselho na avaliação do melhoramento das capacidades militares."

Não obstante, e mantendo o foco no teatro de operações, não há como ignorar a dura atividade das Empresas Militares Privadas (EMP), que se encontram em franca ascensão ${ }^{21}$, tendo voltado a assumir preponderância com o pós-11 de Setembro, de origem e regulamentação estadunidense e britânica. ${ }^{22}$ Se antes o monopólio do uso da força pertencia aos Estados, eixo da segurança internacional, hoje a realidade é assaz diferente.

Mormente conhecidas como Private Military and Security Companies, são companhias que compram e vendem serviços militares e de segurança a nível internacional, englobando atividades como logística, recolha de informações, consultadoria, treino e proteção. O que comummente as caracteriza é o facto de, à semelhança das Forças Armadas,

\footnotetext{
${ }^{20}$ STEPHEN PULLINGER, op. cit.: pp. 8 e ss.

${ }^{21}$ Esta maior mundanização vem no seguimento das políticas neo-liberais que desoneram os Estados inclusive das suas feições beligerantes, ademais passadas já décadas do declarado fim da Guerra-Fria, dado que o adormecimento ideológico também promove a crescente desmilitarização dos Estados. Importam ainda outras causas, como o fim do Apartheid na África do Sul, que deixou sem ocupação alternativa muitos profissionais do sector da segurança, ou o próprio desenvolvimento e investigação privados de armamento militar, adoptante de uma visão claramente merceológica. Cfr. FrANCESCO FrANCIONI, Private Military Contractors and International Law: An Introduction, in «European Journal of International Law», Oxford Journals - Oxford University Press, Volume 19, No. 5, November 2008: pp. 961-963.

${ }^{22}$ Designadamente, nos EUA, a International Traffic in Arms Regulation (ITAR), o Arms Export Control Act (AECA) e o Military Extraterritorial Jurisdiction Act (MEJA); no Reino Unido o Foreign Enlistment Act; e na África do Sul o Regulation of Foreign Military Assistance Act.
} 
poderem recorrer diretamente ao uso da força. Estamos perante verdadeiras empresas, com um fito lucrativo, inseridas num mercado global aberto, sujeitas a concursos públicos, cujo recrutamento é feito recorrendo a bases de dados e pertencendo a conglomerados financeiros.

O facto de se impor aqui uma lógica mercantil leva a uma clara promiscuidade funcional, idem est, são as mesmas empresas que, autoras de consultadorias e de prestação de conselhos para-militares, irão definir as novas necessidades de segurança de acordo com o produto que intentam vender e não necessariamente visando o fito político-social que um Estado tutelaria. Apesar da sua relevância no plano tático e operacional reais, não são ainda visadas pela legislação internacional, decorrendo as limitações da sua atuação dos contratos respetivos. $^{23}$

Para obviar à falta de responsabilidade das EMPs, é desde já urgente torná-las sujeitas ao Direito Internacional, algo que não é feito por conveniência político-económica. ${ }^{24}$ Enquanto isso, as instituições contratantes devem assumir o peso dessa responsabilidade, o que não deixará de reforçar assim a autoridade das EMPs na prossecução das missões designadas. ${ }^{25}$ Deste modo, contratando-as, caberá subsidiariamente à UE assumir formas de reparação que incluem a restituição (restabelece-se a posição que existia antes do ato indevido ter sido cometido), a compensação (cobrindo financeiramente os danos causados) ou a mera satisfação (por exemplo através de um pedido de desculpas formal). ${ }^{26}$

\section{Um breve quadro institucional, de áreas e mecanismos de intervenção}

A propensão para uma ação comum em termos de política externa sempre foi grande no seio europeu, pela sua história bélica, pelo seu elevado nível de interdependência económica, pela herança cultural jurídico-regulativa partilhada ou pela mais intensiva co-participação

\footnotetext{
${ }^{23}$ Os problemas residem particularmente na falta de controlo, no facto de não existir uma verdadeira cultura de peacekeeping e de haver implicações a longo prazo para as partes. Exemplos mediatizados da sua incontrolabilidade são os 17 civis iraquianos mortos a tiro por membros da (extinta) Blackwater em Bagdade em 2007, o vídeo que mostra empregados da Aegis a disparar indiscriminadamente enquanto "conduzem no Iraque" em 2004 ou o abuso de prisioneiros em Abu Ghraib em 2003-2004 que envolve membros da TITAN e da CACI. (Cfr. ANNA LEANDER, The Privatization of International Security, Department of Intercultural Communication and Management - Copenhagen Business School, working paper, 2009, No. 10: pp. 2-6; IDEM, Contractualized Citizenship, Nationalized Contracting, Militarized Soldiering: the Market for Force and the Right to have Protection Rights, texto disponibilizado no seminário «Practices of citizenship and the politics of Insecurity», Lisboa, 2009: p. 21)

${ }^{24}$ MARY FARRELL, EU policy towards other regions: policy learning in the external promotion of regional integration, in «Journal of European Public Policy», Volume 16, No. 8, 2009: pp. 962-963.

${ }^{25}$ Nigel White \& SORCHA MACLEOD, EU Operations and Private Military Contractors: Issues of Corporate and Institutional Responsibility, in «European Journal of International Law», Oxford Journals - Oxford University Press, Volume 19, No. 5, 2008: p. 688.

${ }^{26}$ Ibidem: p. 685
} 
nacional de uma região no Globo numa vasta rede de organizações internacionais: UE, Conselho Europeu, ONU, OTAN, OSCE, et caetera. ${ }^{27}$ Importa assim, por razões de horizonte de reflexão e devida caracterização do imagético Leviatã, traçar um breve sumário de alguns campos de atuação concernentes ao nosso problema, designadamente a Justiça e os Assuntos Internos, em especial sobre o terrorismo (3.1.), o relacionamento com os Estados vizinhos (3.2.) e a ajuda humanitária (3.3.). ${ }^{28}$

\subsection{JAI e EES}

A Justiça e Assuntos Internos (JAI) são uma prioridade na política externa, pois para se garantir o estabelecimento de áreas como a liberdade e a segurança internas há que contar com a cooperação de países terceiros, reforçando o Estado de Direito e o cumprimento de obrigações internacionais, em particular após a abolição das fronteiras internas, o que implica cooperação judicial e políticas nas áreas civis e penais do combate ao tráfico de drogas e pessoas, ao crime organizado, ao terrorismo, às políticas de asilo, et caetera. ${ }^{29}$

O Conselho da UE não deixa de reconhecer ${ }^{30}$ as grandes vantagens económicas daqui advenientes, pois num Mundo de globalização económica e de capitalismo selvagem, é desejável um ambiente político e legal recetivo aos contatos merceológicos internacionais. Ademais, nos princípios deontológicos atinentes aos objectivos da $\mathrm{JAI}^{31}$ reconhece-se que a UE deve fazer uso da sua influente relação com estes países terceiros para os incentivar nesta cooperação internacional, dada a importância que esta matéria tem para a UE e seus EM. A aproximação a estes parceiros deve ser individual e flexibilizada, devendo os EM mobilizar para tal os seus recursos políticos, financeiros e operacionais, promovendo a concertada intervenção da UE. ${ }^{32}$

\footnotetext{
${ }^{27}$ MiCHAEL SMITH, Towards a theory of EU foreign policy-making: multi-level governance, domestic politics, and national adaptation to Europe's common foreign and security policy, in «Journal of European Public Policy», Volume 11, No. 4, 2004: p. 472.

${ }^{28}$ Para uma visão abrangente dos cenários de atuação da UE no Mundo, designadamente nos Balcãs Ocidentais, na Geórgia, na Palestina, em Israel, no Iraque, no Afeganistão, na Moldávia, na Indonésia, na Colômbia e por toda a África, remetemos para os anuais Relatórios Gerais sobre a Actividade da União Europeia e em especial para as informativas monografias oficiais A União Europeia no mundo - A política externa da União Europeia, Luxemburgo: Serviço das Publicações Oficiais das Comunidades Europeias, 2007, e Trabalhar pela Paz, pela Segurança e pela Estabilidade - A Europa no Mundo, Luxemburgo: Serviço das Publicações Oficiais das Comunidades Europeias, 2007.

${ }^{29}$ SANDRA LAVENEX, EU external governance in "wider Europe”, in «Journal of European Public Policy», Volume 11, No. 4, 2004: p. 688.

${ }^{30}$ Nota $14366 / 3 / 05, \S 7$

${ }^{31}$ Ibidem, $\S 9$

32 Ibidem, $\S \S 10-11$
} 
Claro que num Mundo globalizado a cooperação torna-se indispensável, assumindo a ONU e a OTAN ${ }^{33}$ os papéis de parceiros privilegiados. O rumo a uma Nova Ordem Mundial encontra-se delineado: “[a]ctuando em conjunto, a União Europeia e os Estados Unidos podem ser no mundo uma extraordinária força benéfica." ${ }^{34}$ Mas há que ter em mente que hoje já não se combate um inimigo direto, na maioria dos teatros de operações. A comunidade internacional atua como parte terceira dirimindo o conflito, reduzindo o antagonismo dos pólos beligerantes, querendo sim a reconstrução, democratização e desenvolvimento do Estado em flagelo ${ }^{35}$, atendendo ademais a que os conflitos hodiernos se pautam pela sua regionalização, tomando-se a população como um dos atores mais importantes. É esta a “característica principal da resolução de conflitos - terceiros, que não fazendo parte do conflito, utilizam os seus meios para o resolver."36

Importa elencar em particular a Estratégia Europeia em matéria de Segurança (EES), de $2003^{37}$, que tem delineados cinco objetivos/ameaças sobre as quais deve versar afincadamente: (1) terrorismo, (2) proliferação de armas de destruição maciça, (3) conflitos regionais, (4) Estados fracassados e (5) criminalidade organizada. O combate a ser feito está longe de passar pela via estritamente militar, favorecendo-se sim uma abordagem heterogénea. De todos estes pontos, urge dar especial atenção ao (1) terrorismo, empolado como foi a partir do atentado às Twin Towers, conduzindo à intensificação da vigilância e proteção das fronteiras da $\mathrm{UE}^{38}$, como os repetidos episódios trágicos atinentes à FRONTEX não deixam de recordar.

Veramente, em Setembro de 2001 o Conselho Europeu determinou que "o terrorismo representava um verdadeiro desafio para o mundo e para a Europa, tendo decidido que o combate ao terrorismo passaria a ser um objetivo prioritário da União Europeia." ${ }^{39}$ Contudo, e como é característico de uma era dita "pós-ideológica", se durante a Guerra-Fria os intervenientes se encontravam plenamente identificados, no Presente os múltiplos alvos que

\footnotetext{
${ }^{33}$ AJP-3.4.1 - Peace Support Operations: pp. 1-8.

${ }^{34}$ A Europa no Mundo - Trabalhar..., op. cit.: pp. 2-3.

${ }^{35}$ Importa ter em mente nesta matéria a Convention $(V)$ respecting the Rights and Duties of Neutral Powers and Persons in Case of War on Land.

36 ANTÓNIO FERNANDES DE OLIVEIRA, A resolução de conflitos no actual contexto estratégico, texto disponibilizado no seio do «Curso em Operações de Paz e Acção Humanitária» (Faculdade de Direito da Universidade de Coimbra, Ius Gentium Conimbrigae e Exército Português), Coimbra, 2010: p. 4.

${ }^{37}$ Decisão do Conselho 15895/03

${ }^{38}$ KLAUS-DiETER BORChARDT, The ABC of European Union Law, Luxemburg: Publications Office of the European Union, 2010: p. 24.

${ }^{39}$ Decisão do Conselho 2005/671/JAI, consideração (1). Papel nevrálgico desempenha a Decisão do Conselho

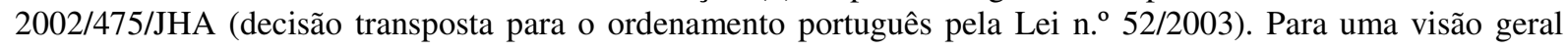
desta temática, são particularmente recomendáveis os anuais EU Terrorism Situation and Trend Reports desenvolvidos pela EUROPOL.
} 
atormentam o Ocidente encontram-se tipificados pela sua falta de individualidade e identidade. Esta padronização, continuamente mediatizada, facilita a conquista da (maioria da) opinião pública, que assim melhor aceita o contínuo ataque ao "inimigo público", quer seja um terrorista da ETA ou do Hamas, quer atue no Reino Unido ou no Afeganistão, quer implique o controlo do Iraque ou ameaças e sanções contínuas ao Irão.

\subsection{PEV, UPM e integração regional}

É bastamente assumido que a UE tem um interesse direto em cooperar com os seus países vizinhos de modo a que estes resolvam os seus problemas internos, tendo no horizonte a própria segurança da União, dado o escalonamento de violências regionais, fluxos migratórios incontroláveis, rutura de fornecimento de energia ou de rotas comerciais, ou ainda de zonas propícias ao desenvolvimento de ações terroristas ou outras atividades criminosas. ${ }^{40}$ Destarte, outro eixo da Política Externa reside no comércio, cuja troca de interesses promove também o pacifismo político-diplomático. O recurso a sanções comerciais é então um meio comum, e por vezes eficaz, de politizar e condicionar as relações com países terceiros. Daqui a importância da Organização Mundial do Comércio, no papel de árbitro regente de litígios entre parceiros comerciais.

Importante pilar que também toca o campo comercial é a Política Europeia de Vizinhança (PEV), nascida de uma iniciativa da Comissão Europeia em $2003^{41}$, que abrange todos os países do Mediterrâneo e do Leste Europeu (com exceção da Rússia), promovendo o estabelecimento de relações económicas e políticas privilegiadas e estáveis. ${ }^{42}$ A sua teleologia prende-se com a construção de um denso diálogo político, facilitando o acesso ao mercado interno da UE e desenvolvendo a cooperação nas áreas da Justiça, Liberdade e Segurança,

\footnotetext{
${ }^{40}$ A Strong European Neighbourhood Policy, Brussels: Commission of the European Communities, 05/12/2007, $\operatorname{COM}(2007)$ 774: p. 6.

${ }^{41}$ Estando os seus princípios estruturais definidos logo em 2004. Já em Dezembro de 2002, em Copenhaga, o Conselho Europeu decidira que a União devia alargar as suas relações com países vizinhos de forma a evitar novas linhas divisórias na Europa e a promover estabilidade e prosperidade dentro e fora das suas fronteiras. (SANDRA LAVENEX, A governance perspective on the European neighbourhood policy: integration beyond conditionality?, in «Journal of European Public Policy», Volume 15, No. 6, 2008: p. 687)

${ }^{42}$ Com a Rússia, para além da concertação económica, a cooperação estende-se aos domínios da investigação, educação e seguranças interna e externa. Já com os Estados árabes da bacia do Mediterrâneo e Israel, deseja-se uma grande zona de comércio livre. É com os EUA, naturalmente, que se encontra o maior vínculo, pois além de comuns interesses comerciais e económicos, comungam do mesmo modelo social e partilham muitas vezes dos mesmos interesses políticos. O que se repercute inelutavelmente na sua cooperação na OTAN.
} 
prosseguindo-se a estabilidade destes países através da promoção sustentável da Democracia representativa, dos Direitos Humanos e do Estado de Direito. ${ }^{43}$

Após a queda do Muro, a UE pôde paulatinamente abandonar a sua "política de exclusão", passando antes para uma "política de inclusão", dada a alteração do mapa geopolítico. ${ }^{44}$ Com a PEV podemos falar de uma "integração parcial" ${ }^{45}$, dado que esta se interconjuga com as parcerias da UE com os países mediterrâneos: se a dimensão bilateral da primeira é mais adequada à promoção de reformas internas, a segunda propicia o contexto e abordagem regionais. ${ }^{46}$ É desejada a projeção dos valores europeus e facilitado o preenchimento das faltas sentidas nos mercados nacionais de trabalho, tudo através de uma coerente política de mobilidade. A UE dá os seus contributos sem se envolver diretamente nas questões conflituosas, promovendo reformas em ambos os lados adversários, visando a convergência dos sistemas legal, político e económico, querendo-se assim formatar a integração social e criar uma certa confiança entre as partes. Não obstante, aqueles mesmos conflitos devem fazer parte do diálogo político.

Importa contudo reforçar que o sucesso da PEV está interconectado com a expectativa que estes países têm de aderir à UE ou ao seu protetorado. Assim, o limite da condição de acesso encontra-se sempre pairando no ar, podendo-se encarar a PEV como uma projeção da dimensão externa das políticas internas da UE. Quando perante áreas politizadas como a JAI, a UE deve usar meios de natureza hierárquica; já quando está face a questões de mera funcionalização, como a política de transportes, é mais avisado promover a rede de governo horizontal que assenta na cooperação entre aqueles Estados. Desta forma a PEV não tem que ser tomada necessariamente como um estádio provisório para inserção na UE, dando-se-lhe alguma autonomia. ${ }^{47}$

Por sua vez, no seguimento da Conferência de Barcelona (1995), que promoveu os diálogos político e sócio-cultural e a cooperação económica, os objetivos da União para o Mediterrâneo (UPM) são o reforço das relações multilaterais, uma maior cooperação entre a UE e os países mediterrâneos, estabelecendo uma governação em termos equitativos, e traduzir todos estes princípios em projetos concretos. É de realçar que a UPM é independente

\footnotetext{
${ }^{43}$ A Strong European ..., op. cit.: p. 7.

${ }^{44}$ SANDRA LAVENEX, EU external governance..., op. cit.: p. 680.

${ }^{45}$ Com o afogamento do conflito ideológico permitiu-se o ressurgir da concepção da UE como um "civilian power", cujo soft power emanaria da projecção exterior das suas virtudes internas através de meios normativos e político-económicos. (Ibidem, p. 684) É o densificar, no fundo, do "european dream".

${ }^{46}$ A Strong European ..., op. cit.: p. 3.

${ }^{47}$ SANDRA LAVENEX, A governance perspective..., op. cit.: pp. 938 e 945-946.
} 
do processo de alargamento da UE. ${ }^{48}$ Contudo, a integração regional serve uma estratégia dual, permitindo a preservação da ordem regional e o desenvolvimento da presença global da UE, exportando o seu modelo de governo, exercendo influência internacional através da dinamização dos seus valores e reforçando a sua identidade própria sem comprometer os interesses nacionais dos diversos EM. É de atentar que a sua promoção não levantou oposições no seio europeu, não obstante as competitivas rivalidades comerciais. ${ }^{49}$

Se a integração regional se dirige, por um lado, a grupos de países por inteiro (por exemplo com a Associação de Nações do Sudeste Asiático, que com alguma relutância vai lidando com a matéria humanitária), por outro, e maioritariamente, passa por acordos bilaterais entre a UE e os seus parceiros, destacando-se a China, a Índia, a África do Sul e o Brasil pelo crescendo de interesses económicos. Importa consequentemente lembrar que a integração regional tem tido mais sucesso na Ásia a partir da sua crise financeira de 1997, tendo antes operado em relacionamentos por "bloco". Já em África a política de integração regional afastou-se das diretivas advenientes dos Acordos de Lomé e Cotonou, pois verificouse que promover a troca comercial ao invés do mero auxílio era mais proveitoso a longo termo, reforçando-se as relações a nível bilateral com os diversos Estados. ${ }^{50}$ A verdade é que esta estratégia, promovendo o relacionamento direto e individual com os Estados ao invés de lidar com estes agrupados, favorece em muito o peso, superioridade e pressão exercida pela UE em detrimento da fragilidade e submissão de Estados com economias ainda emergentes.

\subsection{Ajuda humanitária}

A outra faceta da Política Externa que nos importa elencar é a da ajuda humanitária consagrada explicitamente nos artigos $214^{\circ}$ e $4^{\circ} / 4$ TFUE -, sendo que, através da assistência técnica e monetária a países pobres, a UE protagoniza mais de metade da assistência oficial dada pelos maiores países industrializados em todo o mundo a nível global, tendo um papel maioritariamente financeiro. Inserida nos Objetivos do Desenvolvimento do Milénio, a assistência comunitária visa a autarcia dos Estados pobres, das infra-estruturas ao comércio, das instituições jurídicas às políticas. Esta assistência corporiza-se não só na concertação com os Governos, mas também na cooperação e intermediação de ONGs, auxílio a crises ou apoio direto à sociedade civil.

\footnotetext{
${ }^{48}$ Gaetana Trupiano, The Union for the Mediterranean and Cooperation between the European Union and the Mediterranean Countries, in «The European Union Review», Vol. 14, No. 2-3, 2009: pp. 36 e ss.

${ }^{49}$ MARY FARREL, op. cit: pp. 1169-1171.

${ }^{50}$ Ibidem: pp. 1175-1179.
} 
É sabido como a instrumentalização da ajuda humanitária faz parte da estratégia política na resolução de conflitos, pois diminui os efeitos das ações diretas política e militar. ${ }^{51}$ Isto conduz a que as ONGs sejam associadas a países, blocos ideológicos ou outras forças que os Estados recetores vêem como a causa da sua situação de fragilidade. ${ }^{52}$ Não é à toa que a esmagadora maioria das ONGs pertence ao hemisfério "Norte desenvolvido": a UNHCR estima que cerca de 20 ONGs europeias e norte-americanas recebam aproximadamente $75 \%$ dos fundos públicos consignados para emergências. ${ }^{53} \mathrm{O}$ direto financiamento estatal das ONGs está a aumentar em detrimento da mediação e canalização que as Nações Unidas poderiam fazer, o que, se aproxima os doadores da operacionalidade das instituições e dos reflexos no terreno, também inquina a independência da ajuda humanitária. ${ }^{54}$ Assim, a Comissão tem como mais leais as redes transnacionais de ONGs que financia, em detrimento de outras transgovernamentais. Por consequência o nível de ação das primeiras encontra-se particularmente condicionado, mas nem por isso influenciam mais as negociações dos EM. Por outro lado, estes têm mais facilidade no "shopping", idem est, em optar por outras instituições onde tenham maior oportunidade de participação. ${ }^{55}$

Também a Cooperação Civil-Militar e as operações militares com o intuito de ganhar "hearts and minds" ", idem est, que prestam os mesmos tipos de apoio e ajudas humanitárias, mas que são protagonizadas por militares, contribuem para esbater e mitigar a aura de neutralidade que as ONGs tradicionalmente mantinham. E se é certo que quem privilegia os princípios humanitários consegue ser neutro, tal não pode ser dito da fação militar, que não atua imparcialmente. ${ }^{57}$ A relação com as EMPs é também sui generis, dada a ajuda

\footnotetext{
${ }^{51}$ Significativamente recorrendo às palavras do nosso referente do séc. XVII, "Conquest, is not the Victory it self; but the Acquisition by Victory, of a Right, over the persons of men. He therefore that is slain, is Overcome, but not Conquered: He that is taken, and put into prison, or chaines, is not Conquered, though Overcome; for he is still an Enemy, and may save himself if hee can: But he that upon promise of Obedience, hath his Life and Liberty allowed him, is then Conquered, and a Subject; and not before." (HOBBES, Leviathan: p. 720)

${ }^{52}$ THORSTEN VOLBERG, The politicization of humanitarian aid and its effects on the principles of humanity, impartiality and neutrality, Dissertation on «European Master's Degree in International Humanitarian Assistance», Ruhr: University of Bochun, 2005-2006: pp. 26-29.

${ }^{53}$ Há também uma colisão com a ajuda humanitária islâmica, frequentemente associada ao terrorismo, não obstante a importante assistência que proporciona, nomeadamente de suporte espiritual, como é devido à sua estrutura religiosa. Pelo contrário, as ONGs cristãs são consideravelmente bem aceites, tendo tido grande implementação nos anos 90, especialmente na África Central, no Sudeste Asiático e na América Latina, acompanhando o apoio educacional e a ajuda médica que levam com doutrinamento religioso. (Ibidem: pp. 3032)

${ }^{54}$ Ibidem: pp. 38-39.

${ }^{55}$ SONJA BUGDAHN, Travelling to Brussels via Aarhus: can transnational NGO networks impact in EU policy, in «Journal of European Public Policy», Volume 15, No. 4, 2008: pp. 594-595.

56 SCHR Position Paper on Humanitarian-Military Relations [disponível em $<$ http://www.schr.info/assets/uploads/docs/CivMilSCHR-position-paper-on-humanitarian-military-relations2010.pdf> (consultado em 12-12-2010)]: p. 4.

${ }^{57}$ THORSTEN VOLBERG, op. cit.: p. 5.
} 
humanitária por vezes recorrer à sua contratação $a d$ hoc para obter proteção, o que a longo tempo carreia mais prejuízos do que benesses. ${ }^{58}$

\section{Reflexão apreciativa}

Observámos - de forma breve, mas o mais ilustrativa possível - que a Política Externa da UE, por muito que heterogénea e propiciadora de um vasto leque de benefícios sociais, não deixa de obedecer a um modelo de atuação centrado no seu próprio interesse, alcançando nesse absolutismo uma vastidão de áreas e prosseguindo frequentemente um iter militarista e/ou de conquista: em suma, um Leviatã bem amadurecido. Se este egoístico atuar nada traz de novo à dinâmica das políticas externas de qualquer Estado ou federação, mais importa cogitar as implicações para o seu comum cidadão.

Enquanto europeus, ficamos vinculados à imagem que o nosso macro-decisor político projeta. Se o sentimento de anti-americanismo se desenvolveu nas últimas décadas como reflexo de propósitos declaradamente imperialistas, há que ter presente que o anti-europeísmo é também fomentado ao se enveredar por práticas análogas. Tendo em mente um vero desenvolvimento sustentável, perante o cenário beligerante global que muito provavelmente nos aguarda, é urgente reponderar o hodierno posicionamento hobbesiano em favor de uma atuação que promova verdadeiramente algum pacifismo na comunidade internacional, sem qualquer tipo de agendas ocultas.

O que nos conduz inclusive a discutir o estado da cidadania europeia em caso de um conflito de grande escala. ${ }^{59}$ Se é sabido que há uma proteção comunitária genérica, a discórdia pode nomeadamente surgir quanto ao desejo de querer ser identificado como cidadão de uma superpotência cujas ações estarão em completo desacordo com a posição política e opinião pessoal de um indivíduo em concreto. Será que, em caso de guerra, um cidadão da UE deveria ter a oportunidade de renunciar a esse mesmo status supra-estadual? É que afirmar a cidadania tendo como referente o próprio EM promove a fragmentação da imagem e consciência comunitárias - que serão verdadeira e indubitavelmente postas à prova em caso de um conflito bélico. Sendo certo que a apatridía não é uma via coerente, então os deveres de cidadania inerentes ao macro-contrato social exigem que a atuação externa da UE esteja

\footnotetext{
${ }^{58}$ SCHR Position Paper ..., op. cit.: p. 3.

${ }^{59}$ Como atenta THOMAS HoBBES, "every man is bound by Nature, as much as in him lieth, to protect in Warre, The Authority, by which he is himself protected in time of Peace." (IDEM, Leviathan: pp. 718-719)
} 
pensada para se refletir beneficamente sob os seus cidadãos. Afinal, e na senda de ARISTÓTELES, que mais é um Estado se não os seus próprios cidadãos!?

Estas interrogações refletem-se também na obrigação que os EM têm de sintonizar a sua posição com a UE, não só política, mas também institucionalmente. Este vínculo apaga ainda mais o papel do Estado nacional para com os cidadãos nacionais, servindo como mero intermediário do pólo macro-decisor que radica no escalão comunitário. Logo, se for decidida a entrada em guerra da UE, todos os EM devem encetar esforços nesse sentido, mesmo que tal seja contra o defendido a priori pelo Governo (nacional) no poder, de acordo com a estrutura federalista.

Consideramos que, se são os cidadãos os elementos vivos do macroorganismo/Leviatã que constitui a UE, sob os quais recaem as represálias da imagem emitida por aquela, então devem aqueles igualmente ter um direito de pronúncia sobre a mesma. Seja mediatamente através da fidelização dos seus vários EM à vontade popular, em desrespeito pela letra dos Tratados - mas valorando o interesse concreto dos cidadãos, sobrepondo-se a ratio juris à ratio legis -, ou imediatamente recorrendo a mecanismos vinculativos de democracia participativa, como referendos comunitários ou um modelo qualificado e tempestivo de iniciativa de cidadania europeia. 